\title{
НЕСАХАРНЫЙ ДИАБЕТ
}

\section{И КОМОРБИДНЫЕ НАРУШЕНИЯ ВОДНО-ЭЛЕКТРОЛИТНОГО ОБМЕНА}

\begin{abstract}
Цель исследования: доказать, что формально невысокая заболеваемость и частота несахарного диабета (НД) и других вариантов синдрома полиурии-полидипсии (СПП) не отражают истинную распространенность и клиническую значимость этой патологии. Материал и методы: показаны этиологическое и патогенетическое многообразие СПП, трудности классификации и диагностики. Результаты и выводы: предложены диагностические и лечебные подходы.
\end{abstract}

Ключевые слова: несахарный диабет, водно-солевой дисбаланс.

\section{DIABETES INSIPIDUS AND COMORBID VIOLATIONS OF FLUID-SALT BALANCE}

V.S. LUKYANCHIKOV, MD, Prof.

Moscow Medical Centres HEMA

Aim. To prove that formally low incidence and frequency of diabetes insipidus (ND) and other variants of syndrome poliuriapolydipsia (SPP) did not reflect the true prevalence and clinical significance of such disturbances. Material and methods. Demonstrated etiology and pathogenesis diversity of SPP, difficulties in its classification and diagnosis. Results and conclusions. Proposed diagnostic and therapeutic approaches.

Keywords: diabetes insipidus, fluid-salt imbalance.

\section{ТИПОЛОГИЯ И ЭПИДЕМИОЛОГИЯ НАРУШЕНИЙ ВОДНО-ЭЛЕКТРОЛИТНОГО ОБМЕНА}

Термин «диабет» (от слова «diabaino» - протекаю) предложил древнеримский врач Аретей Каппадокийский для обозначения сахарного мочеизнурения, т. е. сахарного диабета (СД). Однако при СД полиурия, жажда, а также повышенное потребление воды - полидипсия являются вторичными и необязательными симптомами. В то же время для несахарного диабета (НД) и ряда близких ему коморбидных состояний эти три симптома служат не просто главными, но отличительными, по сути синдромообразующими признаками, а для некоторых состояний они служат еще и ведущими патогенетическими факторами. В этой связи термин «диабет» семантически ближе несахарному, чем сахарному, диабету.

Очевидно, что биологическая, даже витальная, значимость водно-электролитного гомеостаза выше, чем у других видов обмена, например энергетического. Без экзогенных энергосубстратов организм жизнеспособен много недель, а при лишении воды - несколько суток. Отсюда жесткая регуляция водно-электролитного гомеостаза. К примеру, суточные вариации основного показателя энергообмена - гликемии превышают 70\%, в то время как главная константа водно-электролитного баланса - осмоляльность крови варьируется в пределах 2\% [1]. При этом отклонения осмоляльности и других констант амбивалентны по отношению к жажде, полидипсии и полиурии, т. е. могут как реализовываться указанными симптомами, так и возникать вследствие этих симптомов. Характерно и то, что клинические и лабораторные стигматы водноэлектролитного дисбаланса нередко самокупируются в результате ситуационной коррекции, т. е. являются адаптационной реакцией, а не патологией. Все это затрудняет типологическую и нозологическую оценку водно-электролитных нарушений.
Очевидно, что diabetes insipidus - «безвкусный диабет» и diabetes mellitus - «сахарный диабет» - термины скорее литературные, чем научные. Типологически для обозначения НД и многочисленных коморбидных синдромов более оправданно групповое название «синдром полиурии-полидипсии» (СПП) [2]. Вместе с тем в ряде случаев первичным нарушением является полидипсия, а полиурия возникает вторично. На этой основе синдромы «полиурии-полидипсии» vice versa «полидипсии-полиурии» разделяют на сольвентную полиурию, связанную с избыточным поступлением растворимых субстанций-сольвентов, и водную полиурию, вызванную избыточным потреблением воды. Одновременно выделяют первичные, вторичные и спонтанные, точнее идиопатические, синдромы. Иногда СПП классифицируют по осмолярности мочи, отмечая изотоническую, гипертоническую и гипотоническую полиурию $[1,3,4]$. Но чаще всего предлагают нозологические классификации на основе этиологии и патогенеза водно-электролитного дисбаланса [1-3, 5]. К сожалению, такие классификации, во-первых, громоздки, а во-вторых, не очень четко разграничивают многочисленные формы СПП (табл. 1). Таким образом, типология и классификация данной патологии по-прежнему трудная и актуальная задача.

Сложно определить и эпидемиологический статус синдромов водно-электролитного дисбаланса. У клиницистов рассматриваемая патология, несмотря на множество причин и механизмов развития, считается редкой. Так, самая частая разновидность СПП - центральный несахарный диабет (ЦНД) имеет заболеваемость 1:25000-30000, а распространенность 0,004-0,01\% [1, 3, 4]. Тем не менее можно утверждать, что в клинической практике НД и другие формы СПП все же не так редки и фиксируются во всех возрастных группах, хотя, как правило, носят характер транзиторных или стертых синдромов, поэтому редко диагностируются. В любом случае клиническая значимость этой патологии сомнений не вызывает. 


\section{ДЕФИНИЦИИ ВОДНО-ЭЛЕКТРОЛИТНОГО ГОМЕОСТАЗА И ЕГО РЕГУЛЯЦИЯ}

Основными показателями для оценки водно-электролитного состояния являются осмотическое давление плазмы крови (ОП), осмотическое давление мочи (ОМ), концентрация в сыворотке крови ионов натрия $\left(\mathrm{Na}^{+}\right)$и калия $\left(\mathrm{K}^{+}\right)$, а также содержание в крови мочевины и общего белка.

Осмотическое давление индуцируют не только перечисленные субстанции, но все содержащиеся в крови сольвенты - глюкоза, кальций и пр., а также патологические субстанции, которые появляются при отравлениях или нарушениях метаболизма. Прямая осмометрия с помощью осмометра учитывает все осмогены. Получаемый показатель называется «осмоляльность плазмы крови» (ОП). Норма ОП 280-300 мОсм/кг.

ОП плазмы можно рассчитать по концентрации в плазме крови основных осмогенов с помощью следующей формулы [6]:

\section{ОП мОсм/л = $2\left[\mathrm{Na}^{+}\right.$ммоль/л + ${ }^{+}$ммоль/л + мочевина ммоль/л + 0,03 (общий белок г/л)].}

Получаемый расчетный показатель осмотического давления крови называют «осмолярность плазмы крови» и обозначают в мОсм/л.

\section{Таблица 1. Классификация синдромов полиурии-полидипсии $[1-4,9,10]$}

\begin{tabular}{|c|c|c|}
\hline Нозологическая форма и этиология & Патогенетический механизм & $\begin{array}{l}\text { Относительная } \\
\text { частота }\end{array}$ \\
\hline ЦЕНТРАЛЬНЫЙ НЕСАХАРНЫЙ ДИАБЕТ & Гипотоническая полиурия & $100 \%$ \\
\hline 1.Идиопатический & Дефект не установлен & $>50 \%$ \\
\hline $\begin{array}{l}\text { 2. Наследственно-генетический: аутосомно-доминантный } \\
\text { или аутосомно-рецессивный синдромы (DIDMOAD и др.) }\end{array}$ & $\begin{array}{l}\text { Синтез неполноценного АДГ или его транспортного белка - нейрофизина } \\
\text { (экспрессия мутантного гена часто неполная и перманентная) }\end{array}$ & $<5 \%$ \\
\hline $\begin{array}{l}\text { 3.Дисфункционально-диспластический: первичные } \\
\text { (хромосомные, генные мутации) или вторичные диспла- } \\
\text { зии мозга: септико-оптическая дисплазия, микроцефа- } \\
\text { лия, голопрозэнцефалия }\end{array}$ & Дефект формирования среднего мозга и/или гипофиза & $<1 \%$ \\
\hline 4. Гестагенный (транзиторный) & Разрушение АДГ плацентарным ферментом аргинин-амин-пептидазой & $<1 \%$ \\
\hline $\begin{array}{l}\text { 5. Органический (повреждение гипоталамо-гипофизар- } \\
\text { ной области головного мозга) }\end{array}$ & $\begin{array}{l}\text { Черепно-мозговая травма, лучевая терапия, хирургическое вмешательство, } \\
\text { опухоли или метастазы, синдром пустого турецкого седла, нейроинфекция } \\
\text { (бактериальная, цитомегаловирус, токсоплазма и др.), аутоиммунная деструк- } \\
\text { ция (гломерулонефрит, синдром Гийена - Барре, инфундибулонейрогипофи- } \\
\text { зит, серповидно-клеточный или волчаночный нефрит), гранулематозы, сосу- } \\
\text { дистая патология (аневризмы, ишемия и апоплексия гипофиза) }\end{array}$ & $35-40 \%$ \\
\hline НЕФРОГЕННЫЙ НЕСАХАРНЫЙ ДИАБЕТ & Гипотоническая или гипертоническая полиурия & нет данных \\
\hline 1. Идиопатический & Дефект не установлен & - \\
\hline 2. Младенческий (транзиторный) & У младенцев до 1 года повышенная активность фосфодиэстеразы в почках & - \\
\hline 3. Наследственно-генетический (врожденный и семейный) & 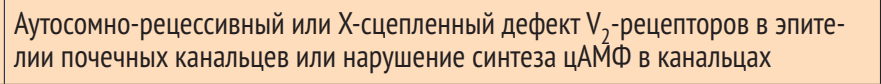 & - \\
\hline 4. Ятрогенный (транзиторная гипертоническая полиурия) & $\begin{array}{l}\text { Препараты лития, карбамазепин, димеклоциклин, амфотерицин: снижение } \\
\text { цАМФ и осмотического градиента в канальцах (осмодиурез при гликозурии, } \\
\text { осмодиуретиках, массивной инфузии сольвентов) }\end{array}$ & - \\
\hline $\begin{array}{l}\text { 5. Вторичный } \\
\text { а) при болезнях почек (изотоническая полиурия) } \\
\text { б) при метаболических расстройствах (гипо- или гипер- } \\
\text { тоническая полиурия) }\end{array}$ & $\begin{array}{l}\text { Пиелонефрит, нефрит и нефроз, амилоидоз, пересадка почки, гидронефроз, } \\
\text { синдром Бернетта, тубулопатии: нарушение действия АДГ, разрушение } \\
\text { нефрона } \\
\text { Гиперкальциемия, гипокалиемия и гипомагниемия: нарушение действия АДГ }\end{array}$ & - \\
\hline ПЕРВИЧНАЯ ПОЛИДИПСИЯ & Гипотоническая полиурия & нет данных \\
\hline 1. Психогения (неврозы, МДП, шизофрения ) & & - \\
\hline $\begin{array}{l}\text { 2. Ятрогения (пристрастие к лечебным чаям и сборам, } \\
\text { прием лекарств, вызывающих сухость во рту и жажду - } \\
\text { антихолинергические препараты, клофелин, фенотиазиды) }\end{array}$ & $\begin{array}{l}\text { снижая градиент осмолярности между эпителием и первичной мочой, что } \\
\text { ведет к обратимому нарушению реабсорбции воды в канальцах }\end{array}$ & - \\
\hline $\begin{array}{l}\text { 3.Дипсогения (снижение порога осморецепторов } \\
\text { гипоталамического центра жажды) }\end{array}$ & $\begin{array}{l}\text { Повышенная активность центра жажды с неутолимой жаждой, вымыванием } \\
\text { электролитов, нарушением градиента осмолярности и водной полиурией }\end{array}$ & - \\
\hline 4. Идиопатическая & Дефект не установлен & - \\
\hline
\end{tabular}


Таблица 2. Условия и факторы, влияющие на секрецию АДГ и его действие в почках

\begin{tabular}{|c|c|c|c|}
\hline Стимуляция секреции & Торможение секреции & Стимуляция действия & Торможение действия \\
\hline $\begin{array}{l}\text { 1. Тошнота } \\
\text { 2. Жажда } \\
\text { 3. Физические нагрузки } \\
\text { 4. Гипогликемия } \\
\text { 5. Повышение осмолярности крови } \\
\text { 6. Уменьшение ОЦК } \\
\text { 7. Снижение АД } \\
\text { 8. Стресс и альфа-адренергическая } \\
\text { активность } \\
\text { 9. Жара } \\
\text { 10. Гипотиреоз, гипокортицизм } \\
\text { 11. Возраст (старение) } \\
\text { 12. Никотин } \\
\text { 13. Ацетилхолин, гистамин, брадики- } \\
\text { нин, ангиотензин II } \\
\text { 14. Опиаты, Апоморфин } \\
\text { 15. Барбитураты } \\
\text { 16. Клофибрат } \\
\text { 17. Аналгетики } \\
\text { 18. Винкристин } \\
\text { 19. Хлорпропамид } \\
\text { 20. Инсулин }\end{array}$ & $\begin{array}{l}\text { 1. Снижение осмотического давле- } \\
\text { ния крови } \\
\text { 2. Увеличение ОЦК } \\
\text { 3. Повышение АД } \\
\text { 4. Холод } \\
\text { 5. Гипоксия и гиперкапния } \\
\text { 6. Предсердный натрий-урический } \\
\quad \text { пептид } \\
\text { 7. Резерпин } \\
\text { 8. Этанол } \\
\text { 9. Налоксан } \\
\text { 10. Фенотиазины } \\
\text { 11. Глюкокортикоиды } \\
\text { 12. Катехоламины } \\
\text { 13. Галоперидол } \\
\text { 14. Антигистаминные средства }\end{array}$ & $\begin{array}{l}\text { 1. Финлепсин (тегретол, карбамазе- } \\
\text { пин) } \\
\text { 2. Хлорпропамид } \\
\text { 3. Клофибрат } \\
\text { 4. Тиазидные диуретики }\end{array}$ & $\begin{array}{l}\text { 1. Сольвентные диуретики, фуросе- } \\
\text { мид, этакриновая кислота) } \\
\text { 2. Соли лития } \\
\text { 3. Падение СКФ } \\
\text { 4. Обструктивная уропатия, пере- } \\
\text { садка почки } \\
\text { 5. Низкое потребление соли } \\
\text { 6. Недостаток белка в диете } \\
\text { 7. Полидипсия } \\
\text { 8. Гиперкальциемия } \\
\text { 9. Гипокалиемия } \\
\text { 10. Амилоидоз почек } \\
\text { 11. Серповидно-клеточная анемия, } \\
\text { плазмоцитома, синдром Шегрена, } \\
\text { волчанка } \\
\text { 12. Диметилхлортетрациклин } \\
\text { 13. Метоксифлуран } \\
\text { 14. Гипергликемия, гликозурия }\end{array}$ \\
\hline
\end{tabular}

Показатель осмолярности на 10-15 мОсм/л меньше показателя осмоляльности. В диагностике главных форм рассматриваемой патологии: центрального несахарного диабета (ЦНД), нефрогенного несахарного диабета (ННД) и первичной полидипсии (ПП) различием между осмоляльностью и осмолярностью можно пренебречь. Но в любом случае предпочтительнее прямая осмометрия.

Осмоляльность мочи (ОМ) также лучше устанавливать методом прямой осмометрии. Вместе с тем и для этого показателя есть аппроксимация, т. е. замена прямой осмометрии расчетом осмолярности мочи по формуле [6]:

ОМ мОсм/л = 33,3 умножить на две последние цифры показателя относительной плотности мочи

В норме осмоляльность мочи в утренней порции (наивысший уровень за сутки) не ниже 300 мОсм/кг (в среднем около 500 мОсм/кг). В зависимости от патогенеза СПП осмоляльность мочи бывает повышенной > 800 мОсм/кг (гипертоническая полиурия), сниженной < 300 мОсм/кг (гипотоническая полиурия) или нормальной 300-800 мОсм/кг (изотоническая полиурия).

Нормативы уровня в крови $\mathrm{Na}+(130-145$ ммоль/л), К+ (4-5 ммоль/л), мочевины (4-8 ммоль/л), общего белка (67-75 г/л) и экскреции электролитов с мочой зависят от возраста, пола, метода определения и других факторов. Эти показатели адаптируют с помощью справочников [7, 8].

Главный регулятор водно-электролитного гомеостаза - гормон гипоталамуса и задней доли гипофиза аргинин-вазопрессин, который чаще называют антидиуретическим гормоном (АДП). Его базальная концентрация в крови составляет 0,3-4 пмоль/л, а при стимуляции уровень возрастает в десятки и даже сотни раз. Функцией АДГ является реабсорбция воды в дистальных канальцах нефрона. На рисунке 1 и в таблище 2 приведены агенты и условия, от которых зависит секреция и действие АДГ. Кроме того, на водно-электролитный гомеостаз прямо, т. е. минуя АДГ, влияют многие другие нервные, обменноэндокринные и ситуационные факторы. Таким многообразием влияний объясняется большое число этиологических и патогенетических вариантов СПП (табл. 3).

\section{ДИАГНОСТИКА НАРУШЕНИЙ ВОДНО-ЭЛЕКТРОЛИТНОГО ГОМЕОСТАЗА}

Клинические проявления всех вариантов СПП практически одинаковы. Это неукротимая жажда и полидипсия, полиурия и поллакиурия. Впрочем их наличие и яркость существенно варьируется в зависимости от этиологии, патогенеза, длительности синдрома, возраста пациента, других факторов и условий. На фоне основных симптомов часто отмечается сухость слизистых и кожи, периферические или тотальные отеки, артериальная гипертензия или гипотония, аритмия сердца, нарушение нервномышечной возбудимости в виде парестезий, мышечной слабости или судорожного синдрома. Специфическая симптоматика наследственно-генетических, соматических, инфекционных и других заболеваний, которые вызвали водно-электролитный дисбаланс или ему коморбидны, дополняет, а чаще ретуширует, т. е. смазывает, клиническую картину.

В целом на клинической основе диагностировать ЦНД, ННД и ПП, а тем более выполнить их дифференциальную диагностику очень сложно. Во-первых, как уже отмечалось, известны стертые, или асимптоматические, формы ЦНД, проявляющиеся небольшой никтурией, а жажда и полидипсия возникают только при ограничении доступа к воде. Во-вторых, у некоторых пациентов, особенно у пожилых людей, снижена чувствительность гипо- 


\section{Рисунок 1. Регуляция водно-электролитного обмена}

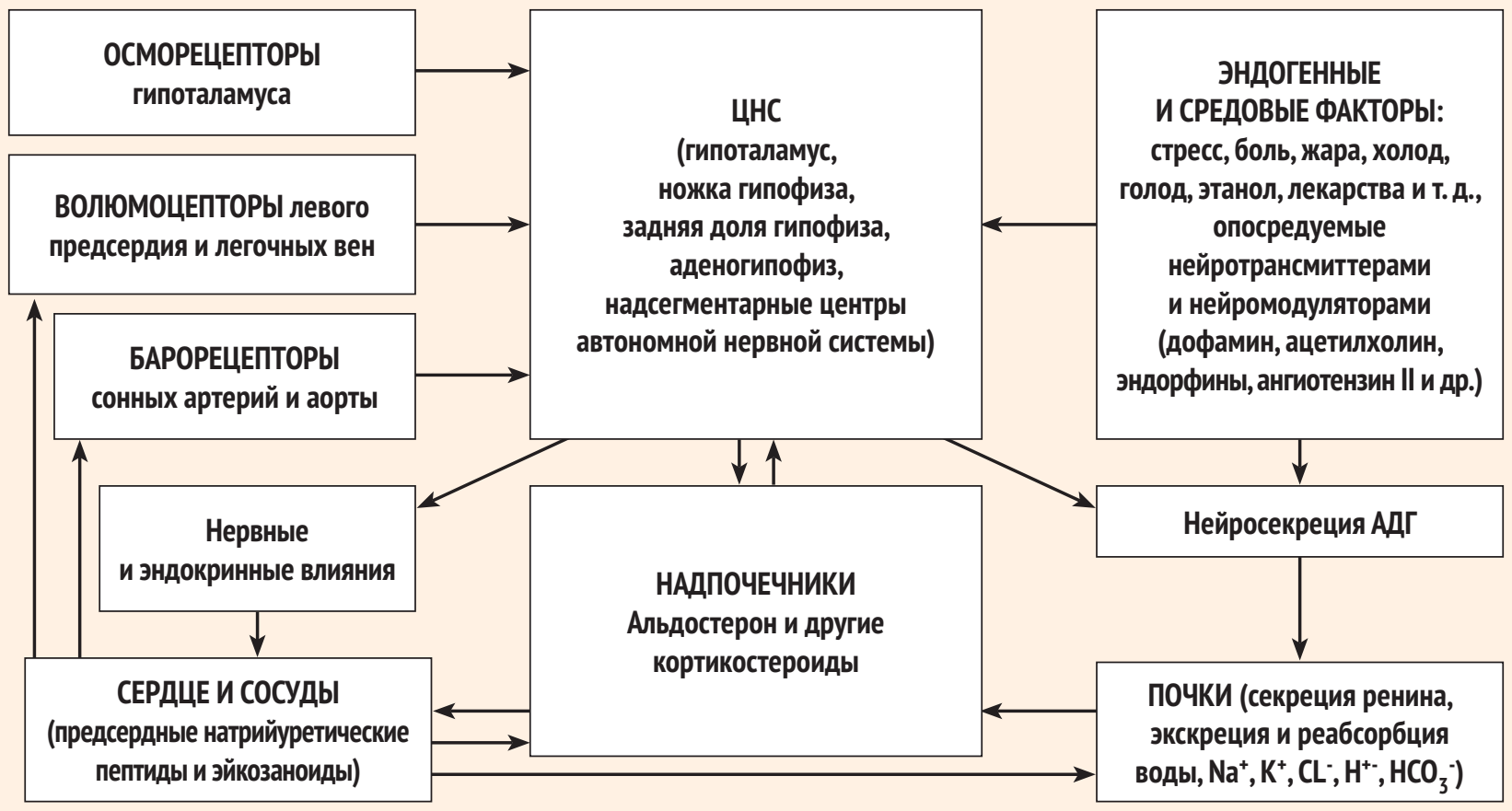

таламического центра жажды, поэтому опорных симптомов - жажды, полидипсии и полиурии фактически нет. Здесь уместно заметить, что чрезмерно большое потребление воды - более 20 литров в сутки - признак психогенной полидипсии $[1,4,5]$.
Подобно клиническим симптомам лабораторные проявления ярче всего у ЦНД. Основными лабораторными признаками СПП являются повышение осмоляльности крови (выше 300 мОсм/кг), гипернатриемия более 150 ммоль/л, низкая относительная плотность

Таблица 3. Оценка пробы с лишением жидкости и введением АДГ при синдромах полиурии-полидипсии [1, 3, 4]

\begin{tabular}{|c|c|c|c|c|c|c|}
\hline \multirow{2}{*}{$\begin{array}{l}\text { Форма СПП } \\
\text { Параметры }\end{array}$} & \multirow{2}{*}{ норма } & \multicolumn{2}{|c|}{ Центральный несахарный диабет } & \multicolumn{2}{|c|}{ Нефрогенный несахарный диабет } & \multirow{2}{*}{$\begin{array}{c}\text { Нервная поли- } \\
\text { дипсия }\end{array}$} \\
\hline & & полный & частичный & полный & частичный & \\
\hline Исходный диурез (мл/кг/час) & $1-5$ & $>5$ & $\geqslant 4$ & $>5$ & $\geqslant 4$ & $>4$ \\
\hline Диурез при лишении воды (мл/кг/час) & $<0,5$ & не меняется & не меняется & не меняется & не меняется & 1 \\
\hline Диурез после АДГ & не меняется & снижается & снижается & не меняется & не меняется & - \\
\hline ОПМ после лишения воды & растет & не меняется & растет $<10 \%$ & не изменяется & растет, $<10 \%$ & растет \\
\hline ОПМ после АДГ & растет & растет, <1,010 & не меняется & не меняется & растет, $<10 \%$ & - \\
\hline Исходная ОП & норма & $>290$ & $>290$ & $>290$ & $\geqslant 290$ & $<280$ \\
\hline ОП после лишения воды & норма $(<290)$ & повышается & повышается & повышается & повышается & повышается \\
\hline Исходная ОМ мОсм/кг & $300-900$ & $>200$ & $<300$ & $<200$ & $<300$ & $<300$ \\
\hline ОМ после лишения воды мОсм/кг & $>750$ & $<300$ & повышается мало & $<300$ & повышается мало & $>300$ \\
\hline ОМ/ОП после лишения воды & $>3$ & $<1$ & $<1=1>1$ & $<1$ & $<1=1>1$ & $>1$ \\
\hline ОМ/ОП после АДГ & $>1$ & $>1$ & $>1$ & $<1$ & $<1=1>1$ & - \\
\hline АДГ после лишения воды & растет & $\begin{array}{c}\text { амбивалентная } \\
\text { динамика }\end{array}$ & низкий & $\begin{array}{c}\text { амбивалентная } \\
\text { динамика }\end{array}$ & повышается & нормальный \\
\hline
\end{tabular}


(1 010 г/л и меньше), низкая осмоляльность мочи (меньше 300 мОсм/кг).

Сравнительно проста диагностика сольвентной полиурии-полидипсии вследствие осмотического диуреза. Распознать синдром помогает анамнез, т. е. прием или инфузия сольвента, и относительно легкое клиническое течение - умеренная полиурия не более 5 литров за сутки, отсутствие неутолимой жажды и эксикоза. Плотность и осмоляльность мочи при этом синдроме не ниже 1010 и 300 мОсм/кг соответственно, но чаще они повышены (гипертоническая полиурия). Верифицирует диагноз обнаружение в моче глюкозы, маннитола, гидрокарбоната или повышенного содержания мочевины, натрия, кальция.

\section{Основными показателями для оценки водно- электролитного состояния являются осмо- тическое давление плазмы крови, осмотическое давление мочи, концентрация в сыворотке крови ионов натрия $\left(\mathrm{Na}^{+}\right)$и калия $\left(\mathrm{K}^{+}\right)$, а также содержание в крови мочевины и общего белка}

Базовые лабораторные симптомы трех вариантов водной полиурии, т. е. ЦНД, ННД и ПП, идентичны. В какой-то мере верифицировать ЦНД помогает определение в крови АДГ, но тест сложен, к тому же не позволяет дифференцировать ННД и ПП. В начальной фазе первичной полидипсии и в некоторых случаях ННД отсутствует никтурия, фиксируется умеренная гипонатриемия и увеличение ОЦК, в то время как ЦНД всегда сопровождается гипернатриемией и сокращением ОЦК. Однако эти отличия кратковременны и маловыражены [10].

Единственным способом дифференцировать основные формы СПП является двухступенчатая функционально-фармакологическая проба с лишением приема воды и назначением десмопрессина [1-5]. Утром в день пробы пациента взвешивают, фиксируют АД и ЧСС, определяют осмоляльность крови и мочи. После этого пациент прекращает пить воду, но может есть сухую пищу. За пациентом ведется непрерывное наблюдение, каждый час фиксируются перечисленные параметры. Проба немедленно прекращается, если масса пациента снизилась больше чем на 5\%, если жажда стала невыносимой, а клинические симптомы дегидратации и гиповолемии резко выражены.

В норме, а также у больных с непродолжительной первичной полидипсией через 2-4 ч осмоляльность мочи сравнивается с осмоляльностью плазмы и превышает 750 мОсм/кг. При ЦНД низкая исходная осмоляльность мочи (50-200 мОсм/кг) в ходе пробы не достигает уровня осмоляльности плазмы, а спустя 3-4 ч наступает плато, когда осмоляльность мочи колеблется в пределах \pm 30 мОсм/кг. Это считается положительным результатом пробы с сухоядением и служит сигналом к окончанию пробы.

Если проба с сухоядением отрицательная, внутривенно, внутримышечно или подкожно вводят 2 мкг десмо- прессина, либо пациенту дают под язык таблетку 0,1 мг десмопрессина, или же вводят интраназально 1 дозу спрея (10 мкг десмопрессина). После этого больному разрешают пить (не более 1,5 литра воды) и через час снова определяют осмоляльность мочи. У пациентов с ЦНД и гестационным НД осмоляльность мочи прирастает более чем на 50\%, при ННД повышение меньше 50\%, но существенно больше 10\%, при первичной полидипсии прирост меньше 10\% [1, 3-5]. Таблица 3 содержит ориентиры для оценки результатов дегидратационно-десмопрессиновой пробы.

Изложенная проба и другие приемы не всегда позволяют дифференцировать многочисленные варианты СПП. К примеру, возможно сочетание ЦНД и ННД, а иногда при первичной полидипсии имеется дефицит АДГ. Нарушение секреции АДГ может быть перемежающимся, варьируясь от глубокого снижения до резкого повышения. Для уточнения формы ЦНД и ННД применяют генетические, бактериальные, иммунологические и морфологические методы, а также МРТ и другие способы визуализации.

Таким образом, диагностика водно-электролитных расстройств - трудоемкий, многоступенчатый и длительный процесс, включающий множество лабораторных, инструментальных и интроскопических методов. Алгоритм диагностики приведен на рисунке 2.

\section{ЛЕЧЕНИЕ СИНДРОМОВ ПОЛИДИПСИИ-ПОЛИУРИИ}

В большинстве случаев СПП применяют производные десмопрессина. Этот синтетический аналог гипоталамического АДГ связывается лишь с V2-рецепторами почечных канальцев, не взаимодействуя с V1-рецепторами в гладких мышцах. Поэтому десмопрессин не повышает артериальное давление и не вызывает спазмы желудка, кишечника и других внутренних органов.

Многочисленные фирменные препараты и дженерики десмопрессина в форме таблеток, спрея, капель и инъекций являются средством выбора для лечения ЦНД и гестагенного НД. При подборе дозы препарата контролируют самочувствие пациента, уровень натрия крови, осмоляльность крови и мочи.

\section{Многочисленные препараты десмопрессина в форме таблеток, спрея, капель и инъекций являются средством выбора для лечения ЦНД и гестагенного НД. При подборе дозы препарата контролируют самочувствие пациента, уровень натрия крови, осмоляльность крови и мочи}

При легком течении ЦНД используют финлепсин (тегретол) 200-600 мг дважды в день или клофибрат 500 мг 4 раза в день.

Нефрогенный НД купируют гипотиазидом 50-100 мг/сут или другими диуретиками, усиливающими экскрецию натрия. Вместе с диуретиками назначают ингибиторы простагландинов (индометацин 25-75 мг, другие несте- 


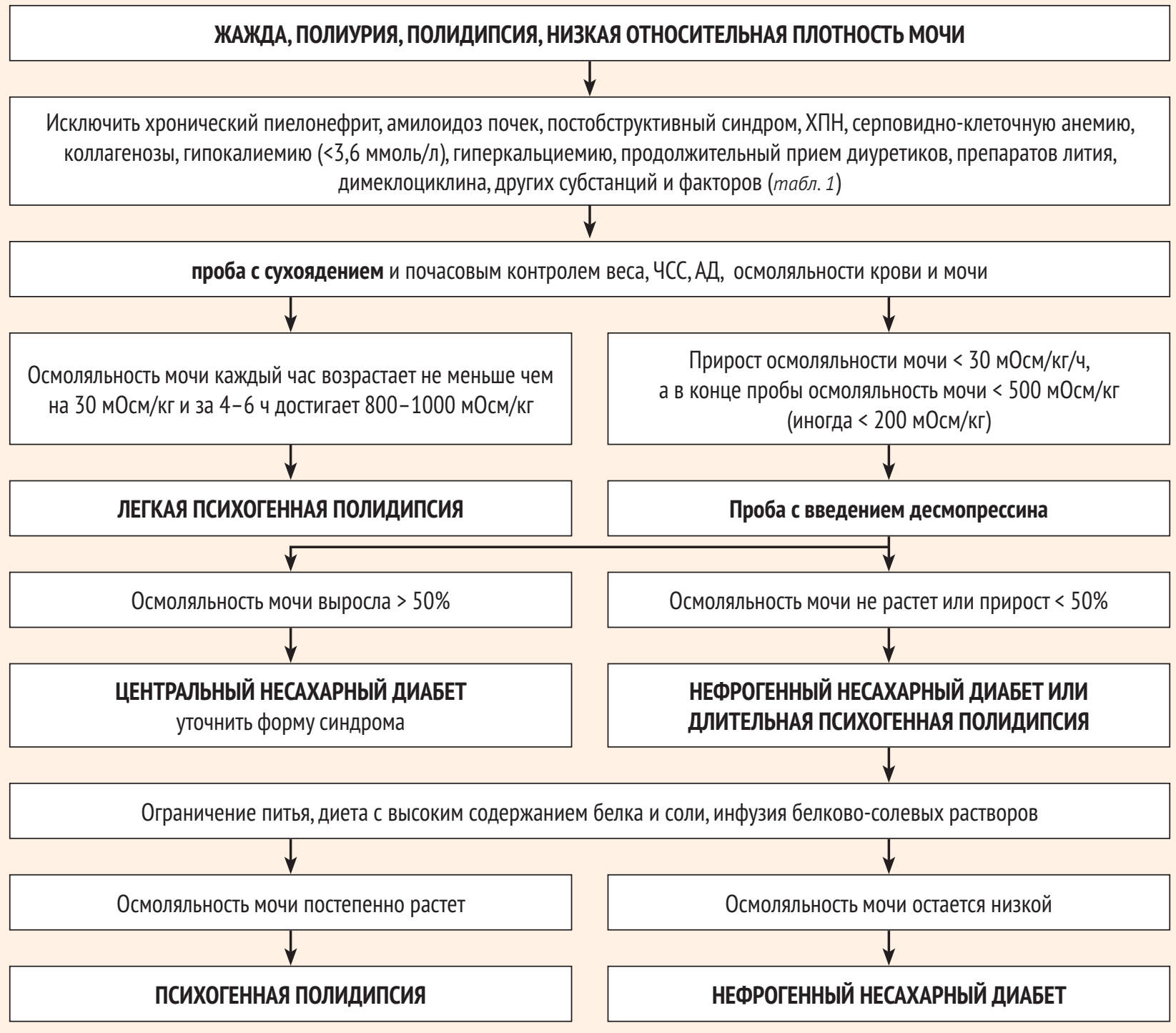

роидные противовоспалительные средства). При этом обязательно ограничивают соль в пище и контролируют сывороточный калий.

Тяжелые формы первичной полидипсии лечат психотропными средствами, белково-солевой диетой, инфузиями белковых и солевых растворов.

Важно, чтобы в каждом случае СПП использовались все средства для уточнения причин и механизмов его развития, что позволяет выбрать эффективное каузальное и патогенетическое лечение.

Своевременная диагностика и коррекция водно-электролитного дисбаланса не только улучшает качество жизни больных, но и предупреждает атонию мочевого пузыря, чреватую гидронефрозом. Это особенно актуально для пожилых людей, у которых из-за нарушения функции центра жажды имеется реальная опасность тяжелой дегидратации с повреждением ЦНС и даже с летальным исходом.

\section{ЛИТЕРАТУРА}

1. Стритен П., Мозес А., Миллер М. Болезни нейрогипофиза. В кн.: Внутренние болезни (пер. с анг.). Ред. Е. Браунвальд и др. М.: Медицина. 1997. Гл. 323: 74-93.

2. Лукьянчиков В.С. Синдром полидипсии-полиурии. В кн. «Эндокринные комы и кризы». М.: Академический проект. 2013. Гл. 7: 230-247.

3. Дзеранова Л.К., Пигарова Е.А. Несахарный диабет. В кн. Эндокринология. Национальное руководство. Ред. И.И. Дедов. Г.А. Мельниченко. 2-е изд. М.: ГЭОТАР Медиа. 2016. Гл. 14: 804-809.

4. Диагностика и лечение эндокринных заболеваний у детей. (Ред. Н.П. Шабалов). 3-е изд. М.: Медпресс-Информ. 2017. 415 с.

5. Доказательная эндокринология (пер. с анг.). Ред. П. Камаго и др. 2-е изд. М.: ГЭОТАР Медиа, 2009.632 с.

6. Корячкин В.А. Формулы и расчеты в интенсивной терапии. СПб.: СПб ГМУ. 2000. 33 c.

7. Липперт. Г. Международная система единиц в медицине (пер. с нем.). М.: Медицина. 1980. 207 с.

8. Кишкун А.А. Клиническая лабораторная диагностика. М.: ГЭОТАР Медиа. 2012.720 с

9. Марино П. Водно-электролитные расстройства. В кн.: Интенсивная терапия (пер. с анг.). М.: ГЭОТАР-Медицина, 1998: 413-469.

10. Джорджи А. Нарушение функции канальцев. В кн.: Руководство по нефрологии (пер. с анг.). Ред.: Д. Витворт, Д. Лоренс. М.: Медицина, 2000: $262-276$ 